\title{
FDG PET Görüntülemelerin Kantitatif Değerlendirilmesi
}

\section{Quantitative Evaluation of FDG PET Imaging}

\author{
Ceren Sezgin ${ }^{1}$, Yasemin Parlak ${ }^{1 *}$, Gözde Mütevelizade ${ }^{1}$, Gül Gümüşer ${ }^{1}$, Elvan Sayıt ${ }^{1}$ \\ ${ }^{1}$ Manisa Celal Bayar Üniversitesi, Tıp Fakültesi, Nükleer Tıp Anabilim Dalı, Manisa, Türkiye \\ e-mail: ceren.sezgin.92@gmail.com,yasemin.gultekin@hotmail.com,gzdyaman@yahoo.com, \\ fggumuser@hotmail.com, elvansayit@hotmail.com \\ ORCID: 0000-0003-2166-4490 \\ ORCID: 0000-0002-3682-7611 \\ ORCID: 0000-0001-5986-8777 \\ ORCID: 0000-0001-7103-2323 \\ ORCID: 0000-0002-3330-1702 \\ *Sorumlu yazar/ Corresponding Author: Yasemin Parlak \\ Gönderim Tarihi / Received: 08.10.2020 \\ Kabul Tarihi / Accepted: 18.01.2021 \\ DOI: 10.34087 /cbusbed. 804272
}

\begin{abstract}
Pozitron emisyon tomografi/ bilgisayarlı tomografi onkolojik vakalarda tanı, evreleme, prognoz ve tedaviye yanıt için giderek artan kullanım alanına sahiptir. PET'in en büyük avantajı radyofarmasötik tutulumunu ölçebilmek ve en çok kullanılan parametre olan standardize tutulum değeri (SUV) şeklinde sayısal sonuç vermesidir. SUV hesaplamaları rekonstrükte edilmiș PET ve BT görüntülerinden elde edilir. 18F-FDG PET/BT bulgularından elde edilen semikantitatif ölçümler (SUV) benign-malign lezyon ayırımında en önemli parametrelerdir. SUV ölçüm farklılıkları, onkolojik hastalarda tedavi yanıtı ve tedavi planlaması için yarı kantitatif bir görüntüleme biyobelirteci olan PET tabanlı ölçümün klinik etkinliğini değiştirir.
\end{abstract}

Öz

Anahtar Kelimeler: Pozitron emisyon tomografi/bilgisayarlı tomografi, standartize edilmiş uptake değeri

\section{Abstract}

Positron emission tomography / computed tomography has an increasing use for diagnosis, staging, prognosis and response to treatment in oncological cases. The major advantage of PET is the ability to measure radiopharmaceutical uptake and it gives digital results in the form of standardized uptake value (SUV). Semi-quantitative measurements (SUV) obtained from 18F-FDG PET / CT findings are the most important parameters in distinguishing between benign and malignant lesions. SUV measurement differences change the clinical efficacy of PET-based measurement, a semi-quantitative imaging biomarker for treatment response and treatment planning in oncologic patients.

Keywords: Positron emission tomography / computed tomography, standardized uptake value

\section{Giriș}

Flor-18 florodeoksiglukoz pozitron emisyon tomografi (F-18 FDG PET/BT) yüksek doğruluğu nedeniyle birçok malignite için primer lezyonun ayırıcı tanısı, evrelemesi ve tedaviye yanıtın değerlendirilmesinde, giderek artan kullanım alanına sahiptir [1]. Yüksek glikoz metabolizmaları nedeniyle, FDG malign hücrelerde biriken sseker eşdeğeri bir bileşiktir [2]. Fizyolojik tutulum gösteren en belirgin bölgeleri değişebilen derecelerde beyin, kalp ve üriner sistemdir. Malign hücrelerde, glikoz metabolizması artar ve buna bağlı olarak FDG tutulumu da zemin aktiviteye oranla artmaktadır [3].
FDG-PET görüntülerinin görsel değerlendirilmesi, tanı ve tedaviye yanıt için çok önemli olmakla birlikte, yarı kantitatif analiz lezyon karakterizasyonu için objektif bir belirteç sağlamaktadır. Tedavi yanıtının izlenmesi standartize edilmiş tutulum değerinin (SUV) değişimi ile ölçülür [4]. PET/BT'de lezyonun benign/malign ayrımında vizüel değerlendirme ve kantitatif yöntemler kullanılmaktadır (SUVmax, SUVmean, metabolik tümör volümü gibi). SUV sadece metabolik bir ölçümdür. Metabolik tümör volümü ise tümörün hacmi ile ilgilidir. Her iki parametrenin birlikte kullanılmasıda doğruluğu artırır [5]. 


\section{Genel Bilgiler}

Standartize edilmiş tutulum değerinin ölçümü semikantitatif bir yöntemdir. Bazı literatürlerde differansiyel absorbsiyon oranı olarak da isimlendirilebilen SUV, bir ilgi alanı (ROI) içerisindeki ortalama aktivitenin $(\mathrm{mCi} / \mathrm{ml})$ enjekte edilen doza $(\mathrm{mCi} / \mathrm{kg})$ bölünmesi ile elde edilir [3-4].

SUV $=\frac{\mathrm{mCi} / \mathrm{mL} \text { (düzeltilmiş bozunma) dokuda }}{\text { a }}$

hastaya enjekte edilen radyofarmasötik mCi/g cinsinden vücut ağırlı̆̆ı

Radyoaktif madde vücutta eşit dağılmadığı için, standardize tutulum değeri rölatif tutulum ölçümüdür, aynı zamanda bir oranı ifade ettiği için birimi yoktur. Radyoaktif madde tüm vücutta eşit dağılsaydı, her alanda ölçülen SUV yaklaşık 1 olurdu.

SUV, hastanın çekim zamanı, plazma glikoz seviyeleri, parsiyel hacim etkileri, rekonstrüksiyon parametreleri, atenüasyon düzeltme metodları gibi birçok faktörle değişebilir. Görüntülerin yorumlanmasında fizyolojik olmayan ve arka plan aktivitesine oranla artmış aktivite tutulumları olan odaklar değerlendirilir. Literatürlerde SUV $>2.5$ olması durumunda lezyonun hipermetabolik olduğunun düşünülmesi gerektiği bildirilmektedir. $\mathrm{Bu}$ hipermetabolik odaklar her zaman tümoral bir lezyon olduğu anlamına gelmez. Genellikle, kan havuzundan (KH) daha yüksek tutulum gösteren lezyonlar maligniteyi düşündürmektedir. Tümör metabolizmasının semikantitatif hesaplanması; KH, mediasten, karaciğer (KC) ve serebellum gibi referans bölgelerdeki F18-FDG tutulumunun lezyon tutulumuna oranı esasına dayanır $[6$, 7].

Beyin (gri madde) normalde yüksek FDG tutulumu gösterir. Kalp, inceleme anındaki metabolik durumuna bağlı olarak farklı miktarlarda tutulum gösterebilir. Üriner sistem FDG nin idrar ile atılması nedeniyle yüksek aktivite gösterebilir. Mide ve barsaklarda da ilaç kullanım, peristaltizm, enflamasyon vb. durumlarda yüksek FDG tutulumu izlenebilir. Çocuklarda timüs ve büyüme plakları rölatif olarak yüksek tutulum gösterirler [8].

PET kantitatif bir görüntüleme tekniği olmasına rağmen, FDG PET/BT'de yaygın olarak kullanılan SUV'u, etkileyen birçok faktör vardır.

\subsection{F-18 FDG tutlumunu etkileyen faktörler}

Vücutta F-18 FDG tutulumunu etkileyen pek çok benign ve malign proçesler mevcuttur. Bazı malign hastalıklarda FDG affinitesi düşüktür. F18 FDG ile yapılan PET/BT görüntülemede artmış ve azalmış tutulum durumları tablo 1 ' verilmektedir. Lezyonun konumu da önemli bir faktördür. Eğer lezyon normalde düşük arkaplan aktivitesi bulunan ( örneğin akciğer) bir bölgede yer alıyorsa hedef arka plan oranı çok küçük bir lezyonun bile görülmesi için yeterli olabilir. Ancak lezyon yüksek aktiviteli bir bölgede (örneğin renal toplayıcı sistem, mesane) yer alıyorsa sinyal kayıpları oluşacağından tespiti zor olabilir [8]. Yalancı negatifliğe yol açan diğer önemli faktör neoplazinin tipi ve derecesidir. Bazı tümörler hipermetabolik olmadıklarından FDG PET görüntülemede izlenmeyebilirler. Bunun örnekleri
Tablo 1. F18 FDG ile yapılan PET/BT görüntülemede artmıs ve azalmıs tutulum

\begin{tabular}{|c|c|}
\hline Artmış Tutulum & Azalmış Tutulum \\
\hline Yüksek tümör grade’i & Benign lezyon, skar \\
\hline Fazla sayıda viable hücre & Nekroz \\
\hline Artmış tümöral kan akımı & Düşük tümör grade' $i$ \\
\hline İnflamasyon & Musinöz tümörler \\
\hline Tümör hipoksisi & $\begin{array}{c}\text { Bronkoalveolar } \\
\text { karsinom }\end{array}$ \\
\hline Radyasyon (akut) & Hiperglisemi \\
\hline Yakın zamanda kemoterapi & Yüksek insülin \\
\hline Yakın zamanda ameliyat & Kronik radyasyon \\
\hline $\begin{array}{l}\text { Otoimmun tiroidit, paratiroid } \\
\text { adenomu }\end{array}$ & \\
\hline Travma, kırık & \\
\hline $\begin{array}{c}\text { Derinin kontominasyonu } \\
\text { (idrar) }\end{array}$ & \\
\hline $\begin{array}{c}\text { İskelet kasları ve kahverengi } \\
\text { yağ dokusu }\end{array}$ & \\
\hline
\end{tabular}

arasında hepatosellüler karsinoma, renal hücreli karsinoma, bronkoalveoler karsinom, karsinoid ve diğer nöroendokrin tümörler yer alır. Tümörün histolojik derecesi de önemli bir faktördür. Düşük dereceli tümörler örneğin gliomlar ve lenfomalar düşükten ortaya kadar değişken bir FDG tutulumu gösterirlerken yüksek dereceli olanlar yüksek derecede FDG tutulumuna sahiptir [2].

Eğer hasta tok veya yüksek insülin seviyesi mevcut ise insulin duyarlı glukoz taşıyıcılarının aktive olmaları ile yağ ve kas dokusunda daha fazla tutulum olmaktadır. Açlıkta çok az FDG yağ dokusuna gider, bu nedenle çoğunlukla bu dokularda düşük SUV değeri $(<1)$ olmaktadır. Buna karşılık açlıkta karaciğer ve kanda SUV değeri daha yüksektir (>1) [8].

SUV'u etkileyen birçok hata kaynağı (kalibrasyon, rezidü FDG aktivitesi gibi) ve bazı teknik, biyolojik faktörler vardır.

\subsection{SUV'u etkileyen biyolojik faktörler}

Standartize edilmiş tutulum değerini etkileyen biyolojik faktörler arasında hasta vücut kitle indeksi, kan glikoz düzeyleri, radyoaktiviteyi tutulum süresi, hasta hareketi/solunumu, hastanın konforu ve inflamasyon sayılabilir. Bu faktörler tablo 2'de verilmiştir. 
Tablo 2. SUV'u etkileyen biyolojik faktörler

\begin{tabular}{|c|}
\hline Faktörler \\
\hline Vücut kitle indeksi \\
\hline Kan glukoz seviyesi \\
\hline Tutulum süresi \\
\hline Hasta hareketi / solunumu \\
\hline Hasta konforu \\
\hline İnflamasyon \\
\hline
\end{tabular}

SUV hesaplamaları vücut ağırlığına göre standardize edildiği için hastanın vücut kitle indeksi ve vücut kompozisyonu SUV ölçümlerinde değişkenliğe neden olur. Vücut kitle indeksi ile SUV arasında pozitif korelasyon vardır [2,9]. Yapılan çalışmalarda, normal karaciğer SUV'unun, 50 ile $110 \mathrm{~kg}$ arasında değișen bir vücut ağırlığına göre yaklaşık \% 50 oranında değiştiği bildirilmiştir [3]. Bir hastanın, tedavi sırasında vücut ağırlığının değişiminin SUV ölçümlerinde değişime neden olması da mümkündür $[10,11]$.

Ortalama radyoaktivite konsantrasyonunun hesaplanmasında hastanın vücut ağırlığı kullanılır. Bu yöntem bireyler arasında FDG'ye aynı afiniteye sahip bir bölgenin aynı SUV ölçümüne sahip olmasını sağlar. Örneğin aynı miktarda FDG, kilolu ve zayıf hastalara enjekte edilirse, kilolu hastanın lezyonunda ölçülen radyoaktivite konsantrasyonunun zayıf hastada ölçülenden daha düşük olması beklenir. Kilolu hastanın tüm vücudundaki ortalama radyoaktivite konsantrasyonu kilo faktörü kullanılarak azaltılır, böylece ölçülen tümör tutulum aynı olmasa bile SUV iki hastanın tümörleri için yaklaşık olarak eşit olacaktır.

Vücutta FDG dağılımı kiloya bağımlıdır. Kilolu hastalar daha fazla vücut yağ yüzdesine sahiptir ve kas dokusu yağ dokusuna göre metabolik olarak daha aktiftir. Yağ vücuttaki diğer dokulara oranla daha düşük oranda FDG tutulumuna sahiptir. Göreceli olarak daha fazla kası olan zayıf bir hastadaki bir lezyon daha düşük bir SUV'a sahip olur, çünkü kas lezyon ile aynı FDG için rekabet eder [12]. Bu nedenle farklı vücut kompozisyonlarına sahip hastalar arasında SUV'ların karşılaştırılması hatalıdır.

FDG metabolizması glikoz metabolizmasının ilk basamakları ile benzerdir. Glikoz ve FDG hücre içerisine glukoz taşıyıcıları tarafından alınır ve heksokinaz tarafından fosfatlanır (Şekil 1). Ancak farklı moleküller olduklarından tutulum, fosforilasyon, defosforilasyon ve hücre dışında difüzyon oranları farklıdır. Klinik görüntülemede bu farklar önemsizdir. Plazma glukozu, hücrelere taşınma ve heksokinaz ile fosforilasyonda FDG ile rekabet eder. FDG tutulumu plazma glukozu ile ters orantıldır. Bu nedenle, FDG enjeksiyonu sırasında serum glukoz konsantrasyonu ölçülmelidir. Eğer serum glukozu yüksekse, onkolojik görüntülemede yanlış sonuçlara neden olabilir. Serum glukozunun $140 \mathrm{mg} / \mathrm{dL}$ 'nin altında olması istenir. SUV ölçümü, serum glukoz seviyesine göre değişiklik gösterir [2].

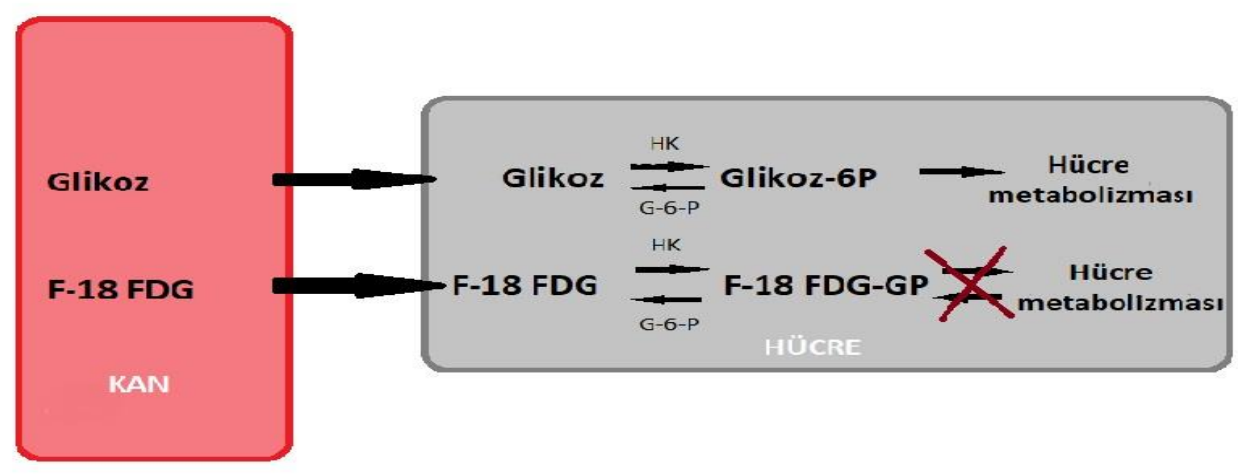

Şekil 1. Glukoz ve F-18 FDG’nin hücresel tutulumu ve metabolizmaları [13].

Glikoz klirens hızı da SUV ölçümünü etkileyen bir faktördür. FDG'nin normal ve enflamatuar dokudaki klirensi, malign dokulardan daha hizlıdır [13]. Normal dokuda standart tutulum değeri enjeksiyondan yaklaşık 60 dakika sonra azalmaya başlar. Tümör dokusunda ise FDG tutulumu aynı zaman diliminde artar. Malign dokulardaki FDG tutulumu zamanla arttığı için, görüntülemeye kadar geçen süre uzadıkça daha yüksek SUV ölçülebilir. Bu nedenle \pm 10 dakika hata payı ile aynı hasta için görüntüleme zamanının aynı olması önerilmektedir [10,14].

Solunum hareketi özellikle abdomen ve akciğerlerden alınan imajlar için SUV ölçümlerini etkileyebilir. Bunun nedeni, genellikle PET görüntüsünün atenüasyon düzeltmesi için kullanılan BT taramasının tek bir nefes tutma sirasinda elde edilebilmesi ancak PET'in tamamlanmasının dakikalar alması nedeniyle nefes tutulmasının mümkün olmamasıdır. Çalışmalar, solunum 
hareketinin diyafram yakınındaki küçük lezyonlar için SUV'un \% 25 azalmasina veya 2 kat fazla olmasına neden olabileceğini göstermiştir. Bu hatalar genellikle lezyon boyutu arttıkça veya solunum hareketi azaldıkça azalır. Solunum hareketleri aynı zamanda görüntüde artefaktlara ve yanlış lokalizasyona da neden olabilir. Solunum hareketinin etkisini azaltmak için, aynı hastayla yapılan her tarama için aynı akuzisyon protokolünü kullanmak önemlidir. Aynı zamanda hastanın taramalar arasındaki solunum düzenini etkileyebilen ve gerçek SUV değişikliklerinin ölçümünü zorlaştıran faktörler arasında hastanın kliniğine bağlı nedenler (örn ateş vb.), kayg1, bekleme odası ve görüntüleme odası fiziksel koşulları da bulunmaktadır [11]. Hasta stresi ve uygun bekleme koşulları kas ve/veya kahverengi yağ dokusunda FDG tutulumunu artırır, bu durumda da düşük tümör/arka plan oranına neden olur [5]. Kahverengi yağ dokusu, termojenezde rol oynar ve glikoz metabolizması yoluyla 1sı oluşturur. En sık servikal, supraklavikuler ve torasik paravertebral alanlarda bulunur. Ayrica aksilla, mediasten ve abdomende de izlenebilir. Tipik görüntüsü nedeniyle nükleer tıp hekimleri açısından kolay ayırt edilebilir olsa da, yüksek FDG tutulumlu kahverengi yağ dokusu benign veya malign lezyonların yanlış değerlendirilmesine neden olabilir ve diagnostik doğruluğu azaltabilir. Sıklıkla genç, kadın ve zayıf hastalarda karşılaşılır [15].

FDG tutulumu tümöre spresifik değildir, tedaviye bağlı inflamatuar değişilikler, benign enfeksiyonlar ve inflamatuar proçesler de fokal radyofarmasötik tutulumuna neden olabilir. Bu odaklar onkolojik PET/BT'de hatalı pozitif sonuçlara neden olabilir. Böyle bir durumla karşılaşıldığında, atipik FDG tutulumunun doğru sebebinin anlaşılması için hasta hikayesi, malignitenin tipik metastaz paterni BT bulgularıyla beraber değerlendirilmelidir [16]. Malign hücrelerde, artmış glukoz transport proteinlerine bağlı tümör içerisinde FDG tutulumu artmış olarak bulunur. Buna benzer durum inflamasyonda da gözlenir. Aktive inflamatuar hücrelerde de artmış glukoz transporter ekspresyonu nedeniyle FDG tutulumu artar. Ayrica inflamatuar durumlarda bazı sitokinlere ve büyüme hormonlarına bağlı deoksiglukozun glukoz transporter afinitesinin arttığı söylenebilir. Ancak bu durum tümör hücrelerinde izlenmez [13].

\subsection{SUV'u etkileyen teknik faktörler}

Standartize edilmiş tutulum değerleri bazı teknik faktörlerden etkilenmektedir (Tablo 3). Bunlar arasında cihaz değişikliği ve kalibrasyonu, görüntü rekonstrüksiyon parametreleri, kontrast madde kullanımı, protez varlığı, yorumlayan hekim farklılıkları sayılabilmektedir. Farklı merkezlerden elde edilen SUV sonuçlarının karşılaştırılması, uygulanan yöntem, görüntü rekonstrüksiyonu ve uygulanan veri analizi prosedürlerindeki olabilecek farklılıklar nedeniyle de önerilmemektedir [4]. PET ve doz kalibratörü arasında doğru çapraz kalibrasyon yapılması SUV'un doğru hesaplanmasını sağlar.
Tablo 3. SUV'u etkileyen teknik faktörler

\section{SUV'u etkileyen teknik faktörler}

Cihaz değişikliği

Görüntü elde etme parametreleri

Rekonstrüksiyon ayarları

Kontrast ajan kullanımı

Farklı uzman yorumu

Doğru hesaplama için hastaya uygulanacak dozun tam olarak bilinmesi gerekir. Bu yüzden enjeksiyon sonrası enjektörde kalan aktivite \%1'i geçmemelidir ya da enjektörde kalan aktivite tekrar ölçülmelidir ve \%1'in üzerinde ise uygulanacak olan dozdan çıkarılmalıdır. Genellikle yapılan çalışmalarda enjektörde kalan aktivitenin \%3'ü geçmediği bildirilmiştir. Enjektörde kalan aktivitenin minimalize edilmesi için uygun volüm ayarlanmalıdır. Düşük volümlerde rezidü aktivite miktarının artabileceği göz önünde bulundurulmalıdır. PET sisteminin saati ve doz kalibratöründe ölçüm yapılan saat arasındaki senkronizasyon da önemlidir. Ayrica enjekte edilen dozun ekstravazasyonu, PET çalışmalarında vizuel değerlendirmeye engel olmazken, hatalı SUV ölçümüne neden olur. [5]

Hastaların takip görüntülerinin farklı cihazlarda yapılması SUV farklılıklarına neden olmaktadır. Farklı üreticilerin farklı tarayıcıları yine farklı fiziksel özelliklere sahiptir. Cihazların kristal boyutları, random düzeltmeler, cihazın TOF yeteneğinin olup olmaması, atenüasyon düzeltme faktörleri farklı olabilir. Aynı zamanda her cihazın kalibrasyon faktörü farklıdır. $\mathrm{Bu}$ durumlar PET/BT tarayıcılarda kantitatif bir değişken olan SUV'u önemli ölçüde değiştirir. Çok merkezli yapılan klinik çalışmalar aynı marka ve modelde dahi PET tarayıcıları arasındaki farklılıkları ortaya koymuştur. Amerika'da 2009 yılında farklı 200 tarayıcı ile yapılan çok merkezli çalışmada da tarayıcı değişikliğinde SUV'un değişebileceği bildirilmiştir [17].

Tablo 4. Akuzisyon parametrelerinin SUV'a etkisi

\begin{tabular}{|c|c|}
\hline Faktör & SUV değişikliği \\
\hline Matriks sayısı & Artar \\
\hline Piksel büyüklüğü & Azalır \\
\hline FOV büyüklüğü & Azalır \\
\hline ROI büyüklüğü & Azalır \\
\hline Akuzisyon zamanı & Artar \\
\hline
\end{tabular}


Görüntü rekonstrüksiyon işlemleri matematiksel olarak kompleks basamaklardan oluşmaktadır. En yaygın olarak kullanılan metodlar, filtre edilmiş FBP (geri projeksiyon) ve iteratif bir yaklaşım olan OSEM (ordered-subsets expectation maximization)'dir. F-18 FDG PET/BT rekonstrüksiyon algoritmaları, görüntü kalitesi üzerinde önemli bir etkiye sahiptir. Rekonstrüksiyon sonrası eğer görüntüler çok gürültülüyse, hastalığı lokalize etmek için daha ileri bir basamakta yumuşatılabilir. Bununla birlikte, yumuşatma komşu imaj piksellerine de ortalama olarak uygulayacağından, çözünürlük kaybına da neden olur, bu yüzden küçük yapılar birbirinden ayırt edilemeyebilir. Bu yüzden gürültü çözünürlük aralığında optimal bir bölge tanımlamak önemlidir. PET/BT rekonstrüksiyon ve akuzisyon parametreleri arasında cihazın görüş alanı, matrix sayısı, smooting filtreler, iterasyon ve subset sayıları yer almaktadır.

Yapılan fantom çalışmaları rekonstrüksiyon parametrelerinin SUV'u yaklaşı \% \% kadar değiştirdiğini ortaya koymaktadır. Matrix sayısı arttıkça SUV artar. Fakat piksel büyüklüğü ile SUV ters orantılıdır. Piksel büyüklüğü artarsa SUV'da azalır. Sabit matriks sayısına sahip görüntülerde daha büyük faydalı görüş alanına (FOV) sahip cihazlarda voksel daha büyük olur [4].

PET/BT'de kontrast kullanımı PET atenüasyon faktörlerinde bir artışa neden olabilir. Yüksek kontrast konsantrasyonlu bölgede F18-FDG konsantrasyonunu olduğundan fazla göstererek SUV'larda artışa neden olacaktır. Kontrast artefakt etkisi verilen ajanın konsantrasyonu ile artar. Klirens, hastaya uygulama yoluna ve BT kayıt zamanı arasındaki farka bağlıdır. Hastaya PET/BT görüntülemesinden birkaç saat önce kontrastlı diagnostik BT çekilmiş ise buna dikkat edilmelidir. Çünkü oral kontrastın doku konsantrasyonu su reabsorbsiyonu nedeniyle zamanla artar. CTAC PET imajlarını düzeltmek için literatürde çeşitli teknikler vardır. $\mathrm{Bu}$ metotlardan birinde kontrast bölgeleri çizilerek, CT'den PET enerjilerine lineer atenüasyon katsayılarına bağlı dönüşüm yapılır ve rekonstrükte edilmiş CTAC PET imajları elde edilir [1].

Rapor değerlendirme sürecinde farklı büyüklükteki ROI'ler ve ROI çizme yöntemleri SUV'u değiştirebilmektedir. ROI'lerin farklı vokseller içermesi SUV ölçümlerinde varyasyon yaratmaktadır. Bu nedenle hastaların takip raporlamalarının aynı doktor tarafından yapılması önerilmektedir [18].Rapor değerlendirme sürecinde farklı büyüklükteki ROI'ler ve ROI çizme yöntemleri SUV'u değiştirebilmektedir. ROI'lerin farklı vokseller içermesi SUV ölçümlerinde varyasyon yaratmaktadır. $\mathrm{Bu}$ nedenle hastaların takip raporlamalarının aynı doktor tarafindan yapılması önerilmektedir [18]

\section{Sonuç}

SUV ölçümleri metabolik aktivitedeki değişiklikleri gösteren kantitatif değerlendirme için uygun yöntemdir. Ancak birçok sınırlamaları vardır. Değerlendirme yapılırken hastaların takip PET/BT çekimlerinin aynı cihazda yapılması, görüntüleme zamanının, rekonstrüksiyon metotlarının standardize edilmesi, cihazın kalibrasyonlarının yapılmış olması, serum glikoz düzeyinin, enjektörde kalan aktivitenin bilinmesi gibi teknik ve biyolojik etkenlerin gözönünde bulundurulması gerekir. $\mathrm{Bu}$ durumlar çalışmanın özgüllüğünü ve duyarlılığını önemli ölçüde etkilemektedir.

\section{Referanslar}

1. Parlak, Y, Gümüşe,r G, Sayit, E, F-18 FDG PET/BT görüntüleme artefaktları, Türk Onkoloji Dergisi 2015, 30(3), 166-171

2. Kelloff, G.J, Hoffman, J.M, Johnson, B, Progress and promise of FDG-PET imaging for cancer patient management and oncologic drug development, Clinical Cancer Research, 2005, 11, 2785-2808

3. Weber, W.A, Wieder, H, Monitoring chemotherapy and radiotherapy of solid tumors, European Journal Nuclear Medicine Molecular Imaging, 2006, 33, 27-37

4. Adams, M.C, Turkington, T.G, Wilson, J.M, Wong, T.Z, A systematic review of the factors affecting accuracy of SUV measurements, American Journal of Roentgenology, 2010, 195(2),310-320

5. Boellaard, R, Oyen, W.J.G, Corneline, J.H, Hoekstra, O.S, Visser, E.P, Willemsen, A.T, Arends, B, Verzijlbergen, F.J, Zijlstra, J, Paans, A.M, Comans, E.F.I, Pruim, J, The Netherlands protocol for standardisation and quantification of FDG whole body PET studies in multi-centre trials European Journal Nuclear Medicine Molecular Imaging, 2008, 35, 2320-2333

6. Parlak, Y, Göksoy, D, Mütevelizade, G, Gümüsser, G, Sayit, E, Baseline SUV Range for Liver and Blood Pool in Patients Undergoing F-18 Fluorodeoxyglucose Positron Emission Tomography/Computed Tomography, Istanbul Medical Journal, $2019,20,(5)$ 431-5

7. Thie, J.A, Understanding the standardized uptake value, its methods, and implications for usage, Journal Nuclear Medicine, 2004, 45,1431-1434.

8. Wahl, R, PET ve PET/BT Prensipler ve Uygulamalar, 2. Baskı, 2011

9. Love C, Tomas MB, Tronco GG, Palestro CJ, FDG PET of Infection and Inflammation, RadioGraphics, 2005; 25,1357-1368

10. Keyes, J.W, SUV: standard uptake or silly useless value? Journal Nuclear Medicine, 1995, 36,1836-1839

11. Adams, M.C, Turkington, T.G, Wilson, J.M, Wong, T.Z, A systematic review of the factors affecting accuracy of SUV measurements, American Journal of Roentgenology, 2010, 195(2),310-320

12. Eskian, M, Alavi, A, Khorasanizadehl, M, Effect of blood glucose level on standardized uptake value (SUV) in 18F- FDG PET-scan: a systematic review and meta-analysis of 20,807 individual SUV measurements, European Journal of Nuclear Medicine and Molecular Imaging, 2019, 46, 224-237

13. Rahmana, W.T, Walea, D.J, Vigliantia, B.L, Townsend, D.M, The impact of infection and inflammation in oncologic 18F-FDG PET/CT imaging, Biomedicine and Pharmacotherapy 2019, 117, 109-168

14. Kinahan, P.E, Fletcher, J.W, PET/CT standardized uptake values (SUVs) in clinical practice and assessing response to therapy, Seminars Ultrasound, CT MR, 2010, 31(6), 495-505

15. Steinberg, J.D, Vogel, W, Vegt, E, Factors influencing brown fat activation in FDG PET/CT: a retrospective analysis of 15,0001 cases. The British Journal of Radiology, 2017; 90, 20170093

16. Carter, K.R, Kotlyarov, E, Common Causes of False Positive F18 FDG PET/CT Scans in Oncology, Brazilian Archives of Biology and Technology, 2007, 50, 29-35

17. Scheuermann, J.S, Saffer, J.R, Karp, J.S, Levering, A.M, Siegel, B.A Qualification of PET scanners for use in multicenter cancer clinical trials; the American College of Radiology Imaging Network experience, Journal Nuclear Medicine, 2009, 50(7), 1187-93

18. Jadvar, H, Parker, J.A, Clinical PET and PET/CT Springer ISBN 9781-84628-100-6, 2008, PET Physics and Instrumentation

http://edergi.cbu.edu.tr/ojs/index.php/cbusbed isimli yazarın CBUSBED başlıklı eseri bu Creative Commons Alıntı-Gayriticari4.0 Uluslararası Lisansı ile lisanslanmıştır. 